\title{
Acute care of severely frail elderly patients in a CGA-unit is associated with less functional decline than conventional acute care
}

This article was published in the following Dove Press journal:

Clinical Interventions in Aging

8 August 2017

Number of times this article has been viewed

\author{
Niklas Ekerstad ${ }^{1,2}$ \\ Synneve Dahlin Ivanoff ${ }^{3}$ \\ Sten Landahl ${ }^{4}$ \\ Göran Östberg ${ }^{5}$ \\ Maria Johansson ${ }^{5}$ \\ David Andersson ${ }^{6}$ \\ Magnus Husberg ${ }^{2}$ \\ Jenny Alwin² \\ Björn W Karlson ${ }^{7}$ \\ 'Department of Cardiology, NU \\ (NÄL-Uddevalla) Hospital Group, \\ Trollhättan-Uddevalla-Vänersborg, \\ ${ }^{2}$ Department of Medical and Health \\ Sciences, Division of Health Care \\ Analysis, Linköping University, ${ }^{3}$ Center \\ of Aging and Health (AGECAP), \\ Section of Health and Rehabilitation, \\ ${ }^{4}$ Department of Geriatrics, The \\ Sahlgrenska Academy at the University \\ of Gothenburg, Gothenburg, ${ }^{5}$ Division \\ of Internal and Acute Medicine, \\ NU Hospital Group, Trollhättan- \\ Uddevalla-Vänersborg, ${ }^{6}$ Department \\ of Management and Engineering, \\ Division of Economics, ${ }^{7}$ Department \\ of Molecular and Clinical Medicine, \\ Institute of Medicine, Sahlgrenska \\ Academy, University of Gothenburg, \\ Gothenburg, Sweden
}

Correspondence: Niklas Ekerstad Department of Cardiology, NU (NÄL-Uddevalla) Hospital Group, Larketorpsvägen, Trollhättan 46100, Sweden

Tel +46736249652

Fax +46 I0 435 7I 29

Email niklas.ekerstad@vgregion.se
Background: A high percentage of individuals treated in specialized acute care wards are frail and elderly. Our aim was to study whether the acute care of such patients in a comprehensive geriatric assessment (CGA) unit is superior to care in a conventional acute medical care unit when it comes to activities of daily living (ADLs), frailty, and use of municipal help services.

Patients and methods: A clinical, prospective, controlled trial with two parallel groups was conducted in a large county hospital in West Sweden and included 408 frail elderly patients, age 75 or older (mean age 85.7 years; $56 \%$ female). Patients were assigned to the intervention group $(n=206)$ or control group $(n=202)$. Primary outcome was decline in functional activity ADLs assessed by the ADL Staircase 3 months after discharge from hospital. Secondary outcomes were degree of frailty and use of municipal help services.

Results: After adjustment by regression analyses, treatment in a CGA unit was independently associated with lower risk of decline in ADLs [odds ratio (OR) 0.093 ; 95\% confidence interval (CI) $0.052-0.164 ; P<0.0001]$, and with a less prevalent increase in the degree of frailty (OR 0.229; 95\% CI 0.131-0.400; $P<0.0001$ ). When ADLs were classified into three strata (independence, instrumental ADL-dependence, and personal ADL-dependence), changes to a more dependence-associated stratum were less prevalent in the intervention group (OR 0.194; 95\% CI 0.085-0.444; $P=0.0001$ ). There was no significant difference between the groups in increased use of municipal help services (OR 0.682; 95\% CI $0.395-1.178 ; P=0.170)$.

Conclusion: Acute care of frail elderly patients in a CGA unit was independently associated with lesser loss of functional ability and lesser increase in frailty after 3 months.

Keywords: frail elderly, comprehensive geriatric assessment, acute care, functional outcomes

\section{Introduction}

\section{Background}

Frailty is a biological syndrome implying reduced physiological reserves and vulnerability to stressors; ${ }^{1,2}$ it is highly associated with functional decline, activity limitations, and prolonged recovery. Moreover, it predicts a high risk of being institutionalized and risk of imminent death..$^{3-7}$ Multiple chronic conditions and recurring acute illness are frequent. Age-related physiological changes, comorbidity, polypharmacy, and functional impairment often interact in a complex manner. Frail elderly patients constitute a high percentage of the individuals treated in specialized acute care units. However, the specific needs of these patients may not be met by the current organization of acute care. 
The prevalence of frailty in older adults has been reported to be as high as $60 \% .{ }^{8}$ Most of the frailty instruments reflect aspects of the clinical phenotype of frailty that focus on one or more of the following core domains: weakness, slowness, low physical activity, unintentional weight loss, and exhaustion. ${ }^{3,9}$ Other instruments focus on the accumulation of deficits. ${ }^{10}$ The FRESH (FRail Elderly Support researcH group) screening instrument has a high degree of specificity and sensitivity. ${ }^{11-13}$

Disabilities - that is, dependence or difficulty carrying out personal or instrumental activities of daily living (ADLs) - could be regarded as adverse outcomes associated with frailty. ${ }^{14-16}$ Functional decline constitutes a loss of independence in self-care activities, including personal and instrumental ADLs. ${ }^{17}$ After admission to hospital, approximately one-third of patients experience a functional decline by discharge, increasing to more than $60 \%$ for patients 90 years or older. ${ }^{18}$ Poor nutrition, insufficient continence care, and in-hospital low mobility have been shown to contribute to this decline. ${ }^{19}$ Dependence in ADL is a crucial outcome in itself, and is considered to be a determinant of other important outcomes such as mortality, living at home, health-related quality of life, re-hospitalizations, and costs. ${ }^{20}$ For elderly acutely hospitalized patients, early rehabilitation is associated with functional benefits..$^{21}$ The current trend in Western societies is to support elderly people to remain independent and in their homes as long as possible. ${ }^{22}$

\section{Importance}

The rationale of comprehensive geriatric assessment (CGA) and care, including early rehabilitation, is to meet the needs of frail patients through an interdisciplinary approach focusing broadly on physiological, psychological, and social factors. ${ }^{23}$ A meta-analysis from 2009 indicated that CGA in an acute geriatric unit could be associated with less functional decline at discharge and a higher probability of living at home. ${ }^{20}$ Similarly, a Cochrane meta-analysis concluded that CGA increases the probability of patients being alive and in their own homes. ${ }^{24}$ Recent trials have indicated that frail elderly individuals could benefit from CGA, in a general context, ${ }^{12,25}$ as well as under more specific conditions (eg, ortho-geriatric care). ${ }^{26}$ A report from the Swedish Agency for Health Technology Assessment and Assessment of Social Care (SBU) found evidence in favor of CGA of frail elderly persons, as well as in the hospital emergency room. ${ }^{27}$ There is, however, a great need to find effective organizational forms of CGA in acute care settings, while giving these patients access to specialized emergency care. ${ }^{28}$ Knowledge regarding the effects of CGA on medium- and long-term patient-health outcomes, such as functional ability, is scarce. ${ }^{20,27}$ Furthermore, we need more knowledge about the effect of CGA on severely frail patients with poor prognosis who often have not been included in previous acute studies.

In 2008, the NU (NÄL-Uddevalla) hospital group - a large county hospital in the Västra Götaland Region of Sweden - introduced two acute elderly care units (MÄVAs) with a total of 48 beds, specializing in the care of elderly patients with multi-morbidity. This care is characterized by a structured, systematic, interdisciplinary CGA conducted on the ward, as described in previous reports..$^{29,30}$ In order to individualize the assessment and treatment, the MÄVA team has a person-centered approach.

\section{Goals of this investigation}

Our aim was to study whether the acute care of frail elderly patients in a CGA unit (MÄVA) is superior to the care in a conventional acute medical care unit when it comes to ADL, frailty, and use of municipal services. We hypothesized that a lower proportion of patients cared for in a CGA unit would report a decline in ADL 3 months after discharge from hospital as compared with patients treated in a conventional care unit. Moreover, we hypothesized that a lower proportion of patients cared for in a CGA unit, compared to conventional care, would present with a higher degree of frailty. Another research question was whether there was any difference between the groups in reported use of municipal services such as home help services, home health care, and residential care.

\section{Patients and methods}

\section{Study design and setting}

This is a clinical, prospective, controlled trial with two parallel groups, carried out at the NU county hospital group between March 2013 and July 2015. The total population of the NU healthcare system is 280,000 inhabitants. The study was approved by an independent ethics committee at the Sahlgrenska University Hospital in Gothenburg, Sweden (8883-12, 20121212) and registered at the Swedish National Database of Research and Development (identifier 113021; November 4, 2012; http://www.researchweb.org/is/vgr/ project/113021).

\section{Selection of participants}

Inclusion criteria: Patients, 75 years or older, in need of inhospital treatment, and who qualified for the foundation of frailty - that is, those who had two or more of the following 
FRESH criteria: general fatigue, tiredness from a short walk, dependence in shopping, frequent falls/anticipation of falls, and three or more visits to the emergency ward during the last 12 months.

Exclusion criteria: A patient clearly suited for care in a conventional acute medical care unit due to the severity and type of condition: acute stroke, acute myocardial infarction, sepsis, or other acute life-threatening conditions; the patient declined participation in the study; informed consent could not be obtained from the patient (and it was not possible to obtain informed consent from a relative); or the patient was a previously defined MÄVA patient (such patients were excluded due to the risk of bias).

When the ambulance staff, or the staff at a primary care clinic, identified a patient who met the inclusion criteria, a senior MÄVA doctor or the on-call doctor was contacted via telephone. If the MÄVA doctor agreed that the patient fulfilled the inclusion criteria, and there was a bed available at MÄVA, the patient was included in the intervention group and admitted directly to MÄVA without passing through the emergency room. In case of unavailability of a bed on the MÄVA wards, the patient was included in the control group and admitted to a conventional acute medical care unit via the emergency room. Allocation was possible 24 hours per day, 7 days per week.

Written informed consent was obtained from the patient, or from a member of his/her next of kin, after oral and written informed consent. All patients eligible for inclusion were registered in a screening-log book. All data were registered and handled in accordance with Good Clinical Practices and legislation.

\section{Intervention}

The two types of hospital units were the intervention and control units. Intervention group: Patients who were cared for in a CGA unit (MÄVA). The MÄVAs are characterized by a structured, systematic interdisciplinary CGA and care by validated instruments focusing on: somatic and mental health, medication review, functional, and activity ability, including early rehabilitation, social situation, and early discharge planning (Figure 1). Patients are admitted directly to the CGA unit via ambulance or primary care. The early rehabilitation strategy involves physicians, nurses, occupational therapists, and physiotherapists as active team members. This implies care guidance that is adjusted to the needs of frail elderly patients. In order to individualize the assessment and treatment, the team has a person-centered approach. These wards work according to the CGA concept and are led by specialists in geriatrics, internal medicine, and, in a few cases, family medicine. The specialists who were not geriatricians all had a special interest in the care of elderly patients.

Control group: Patients who were cared for in a conventional acute medical care unit, where standard procedures in accordance with national and international guidelines

\begin{tabular}{|c|c|c|}
\hline Figures & Comprehensive geriatric assessment and care & Conventional acute medical care \\
\hline Department and facilities & $\begin{array}{l}\text { Two MÄVA (acute elderly care CGA units) wards with a } \\
\text { total of } 48 \text { beds; one, two, or four-bedded rooms } \\
\text { Division of Internal Medicine and } \\
\text { Emergency Care }\end{array}$ & $\begin{array}{l}\text { Wards of internal and emergency medicine; } \\
\text { one, two, or four-bedded rooms } \\
\text { Division of Internal Medicine and } \\
\text { Emergency Care }\end{array}$ \\
\hline $\begin{array}{l}\text { Team members } \\
\text { Physicians }\end{array}$ & $\begin{array}{l}\text { Yes. Specialists in internal medicine, family medicine, } \\
\text { and/or geriatrics }\end{array}$ & Yes. Specialists in internal medicine \\
\hline Licensed practical nurses & Yes. Including specialized admission and discharge nurses & Yes \\
\hline Occupational therapists & Yes & No. Only counseling \\
\hline Physiotherapists & Yes & No. Only counseling \\
\hline Nutritionists & No. Only counseling & No. Only counselling \\
\hline Treatment & $\begin{array}{l}\text { Systematic, structured interdisciplinary comprehensive } \\
\text { geriatric assessment and care by validated instruments } \\
\text { focusing on: somatic and mental health, medication } \\
\text { review, functional and activity ability including early } \\
\text { rehabilitation, social situation } \\
\text { Early discharge planning }\end{array}$ & $\begin{array}{l}\text { Following routines at departments of } \\
\text { internal medicine and emergency care in } \\
\text { accordance with guidelines }\end{array}$ \\
\hline Admission route & Directly to the MÄVA ward via ambulance or primary care & Via the emergency ward \\
\hline
\end{tabular}

Figure I Comparison of the management in the intervention group (CGA) and the control group (conventional acute medical care).

Note: For both groups, standard management procedures in accordance with national and international guidelines were followed. Copyright (C) 20I3. Dove Medical Press. Reproduced from Ekerstad N, Karlson BW, Dahlin-Ivanoff S, et al. Is the acute care of frail elderly patients in a comprehensive geriatric assessment unit superior to conventional acute medical care? Clin Interv Aging. 2017;12:1-9. ${ }^{30}$

Abbreviation: CGA, comprehensive geriatric assessment. 
are applied. All patients were admitted to these care units via the emergency room. Physiotherapists and occupational therapists worked merely on a consultative approach and treat patients only after being actively contacted by physicians or nurses.

\section{Methods and measurements Clinical and demographic characteristics}

The following data were collected: housing, age, sex, heart failure, diabetes mellitus, renal function, other comorbidities and all-cause mortality.

\section{ADL}

ADL independence/dependence was assessed by using the ADL Staircase before discharge. ${ }^{31}$ This instrument comprises five personal ADL (PADL) items (ie, feeding, transferring, going to the toilet, dressing, and bathing), ${ }^{32}$ extended by four instrumental ADL (IADL) items (ie, cooking, shopping, cleaning, and transportation). The instrument is considered clinically relevant and has been validated. ${ }^{33,34}$ The ADL Staircase was administered by interview and, if possible, observation. The assessment was recorded on a threegrade scale: independent, partly dependent, and dependent. Dependence was defined in terms of assistance from another person. Scores ranged from nil to nine dependencies.

\section{Frailty}

The degree of frailty was determined with the FRESH screening instrument. FRESH screening has been developed from the intervention project "Continuum of care for frail elderly people." This instrument has been validated and has manifested high sensitivity and specificity (81\% and $80 \%$, respectively) for screening for frailty in acute settings. The sum of sensitivity and positive prediction is 173 , which is considered an excellent clinical value. It has been used in practice for a few years. ${ }^{11-13}$

\section{The Charlson Comorbidity Index}

The patient's total burden of morbidity was measured by the Charlson Comorbidity Index. ${ }^{35,36}$ It contains 19 categories of comorbidity and predicts the 10-year mortality for a patient. Each comorbidity is assigned a score of 1, 2,3, or 6, depending on the risk of death associated with this condition.

During the index hospital-care episode, clinical and demographic characteristics were collected. Most patients were assessed by an occupational therapist (ADL independence/ dependence) and a nurse (eg, housing). A trained physician made the assessments in a few cases. Follow-up assessments were made 3 months after discharge by a physician at the hospital or in the patient's home. Patients were the primary informants. When necessary, proxy informants were used, mostly a family member.

\section{Outcomes}

The primary outcome was decline in functional activity, assessed by the ADL Staircase, from the index hospitalization until 3 months after discharge. A one-step decline on the ADL Staircase - that is, loss of independence in one or more ADLs - was considered clinically relevant.

In a complementary analysis, the functional abilities of patients were classified into independence, IADLdependence, and PADL-dependence. A decline from independence to ADL-dependence or from IADL- to PADLdependence was considered a clinically relevant change. Being partly dependent was classified as dependence.

A secondary outcome was a one-step higher degree of frailty at 3 months, as measured by the FRESH instrument. The reported use of municipal services was classified into three levels, denoting consecutively increasing dependence: 1) own living without home help services or home health care; 2) own living with home help services or home health care; and 3) residential care. A one-step level increase was considered relevant.

\section{Analysis}

The sample size calculation was based on change in functional capacity measured as the loss of basal ADL according to the Katz Index after 3 months (significance level 0.05, power $80 \%$ ). As previous studies mostly included less frail patients, and had different follow-up times, it was difficult to estimate strict clinically relevant differences. Based on a study along similar lines ${ }^{37}$ and by the use of a two-sided test, it was necessary to include 150 patients in each study group. To compensate for uncertainty, it was estimated that 200 evaluable patients should be included in each group - that is, 400 subjects in total. This is in parity with previous similar studies. ${ }^{20}$

The analysis used the intention-to-treat (ITT) principle that is, the included patients remained in the study group to which they were allocated. After discharge from the index care episode, patients in both groups could be re-admitted to conventional care or the CGA unit.

Statistical analyses were performed using SAS 9.3. Continuous data were compared using Student's $t$-test and categorical data were analyzed using Fisher's exact or chi-square tests. Associations of the intervention with the primary and secondary outcomes were assessed by either Cox regression 
or a multiple logistic regression model adjusted for relevant prognostic variables (sex, age, and the Charlson Comorbidity Index score). A variance inflation factor test was used to analyze all independent variables included in the models for possible collinearity. Variance inflation factor values $>2.5$ were considered indicative of collinearity.

\section{Results}

\section{Characteristics of study subjects}

Between March 2013 and July 2015, the ambulance or primary care teams identified 822 eligible patients. Of these, 408 evaluable patients were included. The mean age was 85.7 years and 56\% were female. Until the 3-month follow-up, 63 patients $(15.4 \%)$ had died. (Figure S1).

Baseline characteristics are presented in Table 1. The two groups did not differ significantly in terms of age, sex, percentage living alone, or scores of ADL and frailty. Both groups were heavily affected by diseases, particularly cardiovascular disease. Patients in the intervention group presented with a significantly higher burden of comorbidity compared with the control group, and Charlson Comorbidity Index scores were 7.4 versus $6.2(P<0.001)$. With regard to the percentage of participants living without home help services, there was a trend toward a significant difference [intervention group, $\mathrm{n}=60$ (29\%); control group, $\mathrm{n}=78$ (38\%); $P=0.054$ ].

\section{Main results}

At the 3-month follow-up, decline in ADLs according to the ADL Staircase was less prevalent in the intervention group [24 (14.1\%); $n=170]$ than in the control group [98 (63.6\%); $\mathrm{n}=154 ; P<0.0001$, Table 2]. Reported ADL Staircase changes are illustrated in Figure 2. For the control group, the average change was 1.1 step (SD 1.6) down the ADL Staircase. For the intervention group, the average change was 0.2 step (SD 1.1) up, that is, the majority presented with no change in ADL.

When ADLs were classified in three strata (independence, IADL-dependence, and PADL-dependence), changes to a more dependence-associated stratum were less prevalent in the intervention group [11 $(6.3 \%) ; n=176]$ than in the control group [33 (20.2\%); $\mathrm{n}=163 ; P=0.0001]$.

Table I Baseline characteristics of the intervention and control groups

\begin{tabular}{|c|c|c|c|}
\hline Characteristic & $\begin{array}{l}\text { Intervention } \\
\text { group (CGA unit) }\end{array}$ & $\begin{array}{l}\text { Control group } \\
\text { (conventional care) }\end{array}$ & $P$-value \\
\hline No & 206 & 202 & \\
\hline Age, $y$, mean (SD) & $85.7(5.3)$ & $85.6(5.4)$ & 0.850 \\
\hline Sex, female, n (\%) & $122(59)$ & $108(53)$ & 0.241 \\
\hline Living alone, $\mathrm{n}(\%)$ & $139(67)$ & $132(65)$ & 0.649 \\
\hline Own living without home help services, n (\%) & $60(29)$ & $77(38)$ & 0.055 \\
\hline Own living with home help services, $n(\%)$ & $113(55)$ & $99(49)$ & 0.237 \\
\hline Own living with home healthcare, $n$ (\%) & $63(3 \mathrm{I})$ & $59(29)$ & 0.762 \\
\hline Living in special housing, $\mathrm{n}(\%)$ & $29(14)$ & $24(12)$ & 0.604 \\
\hline$A D L$, mean $(S D)$ & $4.8(2.5)$ & $4.5(2.5)$ & 0.216 \\
\hline Frailty screening score, mean (SD) & $3.5(0.9)$ & $3.4(0.9)$ & 0.149 \\
\hline Charlson Comorbidity Index score, mean (SD) & $7.4(2.1)$ & $6.2(1.5)$ & $<0.001$ \\
\hline Ischemic heart disease, $\mathrm{n}(\%)$ & $57(28)$ & $67(33)$ & 0.227 \\
\hline Chronic heart failure, $\mathrm{n}(\%)$ & $90(44)$ & $74(37)$ & 0.146 \\
\hline Chronic obstructive pulmonary disease, $\mathrm{n}(\%)$ & $37(18)$ & $40(20)$ & 0.635 \\
\hline Dementia, n (\%) & $20(10)$ & $27(13)$ & 0.247 \\
\hline Malignant disease, $\mathrm{n}(\%)$ & $40(19)$ & $27(\mid 3)$ & 0.099 \\
\hline Anemia, n (\%) & $104(50)$ & $108(53)$ & 0.547 \\
\hline Renal impairment, ${ }^{*} \mathrm{n}(\%)$ & $193(94)$ & $163(81)$ & $<0.001$ \\
\hline \multicolumn{4}{|l|}{ Reported reasons for admission, $\mathrm{n}(\%)$} \\
\hline Dyspnea & $67(32)$ & $65(32)$ & \\
\hline Worsened general condition/tiredness & $48(23)$ & $43(21)$ & \\
\hline Pain & $29(14)$ & $24(12)$ & \\
\hline Fever/infection & $28(14)$ & $40(20)$ & \\
\hline Vertigo/falling & $27(13)$ & $30(15)$ & \\
\hline Others & $52(25)$ & $35(17)$ & \\
\hline
\end{tabular}

Notes: *Defined as glomerular filtration rate $<90$. In both groups, the five most frequently reported reasons for admission were dyspnea, worsened general condition/ tiredness, pain, fever/infection, and vertigo/falling. For some of the patients, more than one reason for admission was reported. No statistical comparisons were conducted. Copyright (C) 2013. Dove Medical Press. Reproduced from Ekerstad N, Karlson BW, Dahlin-Ivanoff S, et al. Is the acute care of frail elderly patients in a comprehensive geriatric assessment unit superior to conventional acute medical care? Clin Interv Aging. 2017;12:1-9.30

Abbreviation: ADLs, activities of daily living. 
Table 2 Unadjusted outcomes reported at follow-up (3 months)

\begin{tabular}{llll}
\hline Outcomes & $\begin{array}{l}\text { Intervention } \\
\text { group } \\
\text { (CGA-unit) } \\
\mathbf{n}=\mathbf{2 0 6}\end{array}$ & $\begin{array}{l}\text { Control group } \\
\text { (conventional } \\
\text { care) }\end{array}$ & $\begin{array}{l}\text { P-value } \\
\mathbf{n}=\mathbf{2 0 2}\end{array}$ \\
\hline Decline in ADLs & $24(14.1 \%)$ & $98(63.6 \%)$ & $<0.0001$ \\
(ADL Staircase) & $\mathrm{n}=170$ & $\mathrm{n}=154$ & \\
Decline in ADL & $\mathrm{II}(6.3 \%)$ & $33(20.2 \%)$ & $0.000 \mathrm{I}$ \\
stratum** & $\mathrm{n}=176$ & $\mathrm{n}=163$ & \\
Increase in degree & $24(13.6 \%)$ & $66(41.0 \%)$ & $<0.0001$ \\
of frailty*** & $\mathrm{n}=177$ & $\mathrm{n}=161$ & \\
Increase in use of & $36(20.0 \%)$ & $44(26.2 \%)$ & 0.170 \\
municipal services & $\mathrm{n}=180$ & $\mathrm{n}=168$ & \\
\hline
\end{tabular}

Notes: The two groups did not differ significantly at baseline in terms of ADLs and frailty $(P>0.05)$. *Decline in ADLs refers to a minimum one-step decrease in independence according to the ADL Staircase. Patients were excluded from the analysis if information was missing or not classifiable at index and/or follow-up. **Decline in ADL stratum refers to a change to a more dependence-associated stratum (independence, IADL-dependence, and PADL-dependence). Patients were excluded from the analysis if information was missing at index and/or follow-up. ****Increase in frailty refers to a minimum one-step increase on the FRESH frailty instrument. Patients were excluded from the analysis if information was missing at index and/or follow-up. Abbreviations: ADLs, activities of daily living; FRESH, FRail Elderly Support researcH group; IADL, instrumental ADL; PADL, personal ADL.

Increase in the degree of frailty was less prevalent in the intervention group [24 (13.6\%); $\mathrm{n}=177]$ than in the control group [66 (41.0); $\mathrm{n}=161 ; P<0.0001]$.

The two groups did not differ significantly after 3 months in terms of proportion of patients reporting increased use of municipal services $(P>0.05)$.

There was no difference in unadjusted mortality after 3 months, with 27 deaths (13\%) in the intervention group and $36(18 \%)$ in the control group $(P>0.05){ }^{30}$

In multiple logistic regression analyses, treatment in a CGA unit was independently associated with lower risk of a decline in ADLs (odds ratio [OR] 0.093; 95\% confidence interval [CI] 0.052-0.16; Table 3). Similarly, when ADLs were classified in three strata (independence, IADLdependence, and PADL-dependence), the reported changes to

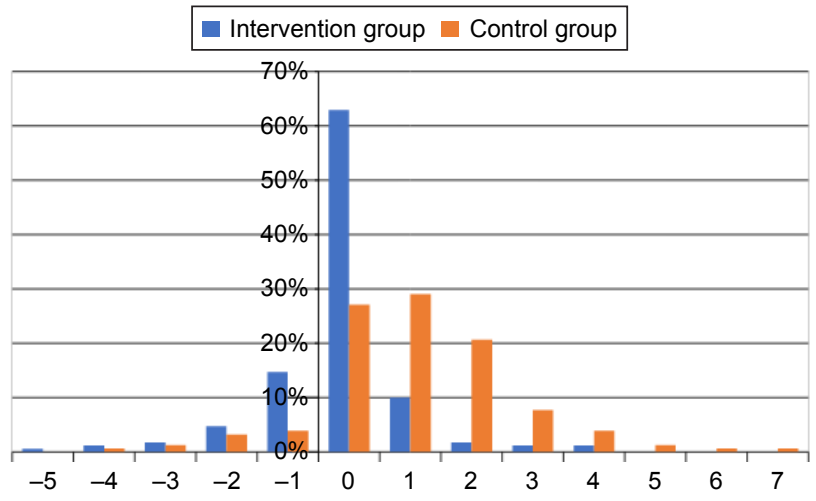

Figure 2 Change in ADLs in the two groups between the index-care episode and the 3-month follow-up.

Note: Negative figures denote improved ADLs.

Abbreviation: ADLs, activities of daily living.
Table 3 Adjusted analysis by multiple logistic regression of risk of decline in ADLs until follow-up (3 months)

\begin{tabular}{lll}
\hline & OR $(95 \%$ CI) & P-value \\
\hline Clinic & & \\
$\quad$ CGA unit (intervention group) & $0.093(0.052-0.164)$ & $<0.000$ I \\
$\quad$ Conventional care (control group) & REF & \\
Sex & & \\
$\quad$ Female & $1.358(0.775-2.382)$ & 0.285 \\
$\quad$ Male & REF & \\
Age & $1.031(0.981-1.084)$ & 0.231 \\
Charlson Comorbidity Index score & $0.955(0.803-1.136)$ & 0.601 \\
\hline
\end{tabular}

Notes: Decline in ADLs refers to a minimum one-step increase of dependence according to the ADL Staircase. OR indicates odds ratio. Patients were excluded from the analysis if information of ADL score was missing at index and/or follow-up. Age, sex, and Charlson Comorbidity Index score were potential confounders and used as covariates. They were tested for collinearity with the use of the variance inflation factor. All variables had a variance inflation factor value $<2.5$, which does not indicate collinearity.

Abbreviations: ADLs, activities of daily living; REF, reference.

a more dependence-associated stratum were less prevalent in the intervention group (OR 0.194; 95\% CI 0.085-0.444).

Increases in the degree of frailty were less prevalent in the intervention group than in the control group (OR 0.229; 95\% CI 0.131-0.400; Table 4).

There was no significant difference in reported increase in use of municipal services between the two groups (OR 0.682 ; $95 \%$ CI $0.395-1.178)$.

\section{Discussion}

Our study shows that acute care for frail elderly patients with acute medical disorders in a CGA unit is superior to care in a conventional acute medical care unit in terms of functional outcomes at the 3-month follow-up. Acute care in a CGA unit was independently associated with less decline in independence in ADLs and less increase in degree of frailty.

Table 4 Adjusted analysis by multiple logistic regression of increase in degree of frailty until follow-up (3 months)

\begin{tabular}{lll}
\hline & OR (95\% Cl) & $P$-value \\
\hline Clinic & & \\
$\quad$ CGA unit (intervention group) & $0.229(0.131-0.400)$ & $<0.000$ I \\
$\quad$ Conventional care (control group) & REF & \\
Sex & & \\
$\quad$ Female & $0.864(0.509-1.467)$ & 0.588 \\
$\quad$ Male & REF & \\
Age & $0.996(0.950-1.045)$ & 0.876 \\
Charlson Comorbidity Index score & $0.995(0.842-1.175)$ & $0.95 I$
\end{tabular}

Notes: Increase in frailty refers to a minimum one-step increase on the FRESH frailty instrument. OR indicates odds ratio. Patients were excluded from the analysis if information of frailty score was missing at index and/or follow-up. Age, sex, and Charlson Comorbidity Index score were potential confounders and used as covariates. They were tested for collinearity with the use of the variance inflation factor. All variables had a variance inflation factor value $<2.5$, which does not indicate collinearity.

Abbreviations: FRESH, FRail Elderly Support researcH group; REF, reference. 
In our trial, severely frail elderly patients with acute medical, non-surgical illnesses were included. To our knowledge, former studies focusing on the CGA concept have not included patients who were this old with such a high total morbidity burden. Our results, therefore, add to the knowledge concerning a potentially appropriate emergency care organization that meets the needs of these patients in terms of relevant outcomes, evaluated with well-established instruments. The generalizability of the results to other hospitals is enhanced by the fact that this trial was integrated in the standard daily clinical context and included a wide spectrum of diagnoses. Furthermore, we studied frail elderly patients in need of acute care, which adds complementary knowledge to former studies on patients in a more chronic and stable phase. Frail elderly patients with similar characteristics as in our study constitute a large part of everyday hospital care consumption, which emphasizes a particular need to study this important patient group.

Treatment in a CGA unit was associated with a significantly lower risk of functional decline, measured by the ADL Staircase, at the 3-month follow-up. Similarly, when ADLs were classified into three strata (independence, IADL-dependence, and PADL-dependence), decrease to a more dependence-associated stratum was less prevalent in the intervention group. This agrees with the results of a few previous studies of elderly patients. ${ }^{12,24-27}$ It should be emphasized that home and hospital CGA programs have been reported to be consistently valuable for several outcomes of elderly patients, whereas CGA performed in other settings have shown diverging results. ${ }^{38}$

Increases in the degree of frailty were less prevalent in our intervention group. As dependence or difficulty carrying out ADLs is associated with frailty, ${ }^{8,14,15}$ this seems to be a reasonable and consistent finding.

One reason as to why there was no difference between the groups in the increased use of municipal services at 3 months may be that this outcome is influenced not only by the patients' ADLs, but also by administrative and socioeconomic issues such as the supply of municipal home help services and rooms in residential care. In addition, participants who died before follow-up were excluded in the analysis, which is likely to imply a conservative estimation. As a co-variation between mortality and dependence in ADLs can be assumed, the control group with higher mortality is likely to gain from the chosen analysis strategy.

Frail elderly patients in acute care have complex needs. They would, therefore, be likely to benefit from a complex intervention, including a biopsychosocial approach.
The CGA and related care constitutes such an intervention. There may be several critical differences compared to conventional care, which may interact and benefit frail elderly patients. In our study, patients in the intervention group were directly admitted to the CGA unit, without passing through the emergency room unlike the control group patients. This is one difference in care, which may play a role in the difference in outcomes, maybe by reducing time to initiation of acute treatment. However, the early rehabilitation perspective, including assessment and care, should be regarded as the most crucial aspect.

One question to address in future research is whether the reported benefit for very frail patients persists in a longterm perspective. More research is also needed to identify appropriate organizational forms adapted to the different stages of needs that frail elderly patients can manifest - that is, stable chronic disease and acute illnesses. This further research should include comprehensive evaluations of activities in primary and municipal care, ambulant geriatric care units, and specialized hospital care. Some of the frail elderly patients will still need organ-specific, highly technological treatments. A future challenge is the search for a strategy to coordinate and integrate specialized interventions with the CGA approach.

The MÄVA form of care constitutes one example of how acute care for frail elderly individuals can be organized. This example could be implemented in everyday hospital health care in Sweden and other countries. Frail elderly patients would thereby be offered more appropriate emergency care than they are at present.

Approximately half of the eligible patients took part in the study, which could be looked upon as a limitation. There was, however, no difference in this respect between the groups, and the main reason was that patients declined to participate in the study.

It was considered very important to include patients who are representative of the frail elderly population in everyday health care. A significant proportion of these patients are cognitively impaired, especially in the acute stage of the illness. For these reasons, randomizing through a lottery, after obtaining informed consent in the ambulance, was considered utterly difficult to implement. As two hospital care forms were evaluated, blinding of patients or staff was not possible. As most of the baseline characteristics did not differ between the groups, the allocation procedure we used seems to be confirmed as random to a satisfactory extent. We believe that a patient allocation sequence which was unpredictable was generated, and that this sequence was concealed 
from the investigators enrolling patients in the study. When differences were identified, patients in the intervention group were slightly more ill (eg, presenting with a higher Charlson Comorbidity Index score), with no identified bias in favor of the intervention group. However, the absence of a lottery procedure constituted a potential risk of bias.

It is a weakness that the assessments could not be carried out in a blinded fashion, and this could potentially have influenced a few of the outcomes. However, in practice, it would have been very difficult to blind the assessors.

\section{Conclusion}

Team-based emergency care for frail elderly patients with acute medical disorders in a CGA unit is superior to the care in a conventional acute medical care unit in terms of clinical functional outcomes. The emergency care in a CGA unit was independently associated with less decline in independence in ADLs and less increase in degree of frailty at 3 months. The likelihood for patients in the intervention group to avail increased use of municipal services was the same as for patients in the control group.

\section{Acknowledgments}

This study was funded by grants from the Healthcare sub-committee, Region Västra Götaland; Department of Research and Development, NU Hospital Group; and the Fyrbodal Research and Development Council, Region Västra Götaland, Sweden.

\section{Disclosure}

The authors report no conflicts of interest in this work.

\section{References}

1. Bergman H, Ferrucci L, Guralnik J, et al. Frailty: an emerging research and clinical paradigm - issues and controversies. J Gerontol A Biol Sci Med Sci. 2007;62(7):731-737.

2. Morley JE, Vellas B, van Kan GA, et al. Frailty consensus: a call to action. J Am Med Dir Assoc. 2013;14(6):392-397.

3. Fried LP, Tangen CM, Walston J, et al; Cardiovascular Health Study Collaborative Research Group. Frailty in older adults: evidence for a phenotype. J Gerontol A Biol Sci Med Sci. 2001;56(3):M146-M156.

4. Rockwood K, Song X, MacKnight C, et al. A global clinical measure of fitness and frailty in elderly people. CMAJ. 2005;173(5):489-495.

5. Ekerstad N, Swahn E, Janzon M, et al. Frailty is independently associated with short-term outcomes for elderly patients with non-STsegment elevation myocardial infarction. Circulation. 2011;124(22): 2397-2404.

6. White HD, Westerhout CM, Alexander KP, et al; TRILOGY ACS investigators. Frailty is associated with worse outcomes in non-STsegment elevation acute coronary syndromes: insights from the TaRgeted platelet Inhibition to cLarify the Optimal strateGy to medicallY manage Acute Coronary Syndromes (TRILOGY ACS) trial. Eur Heart J Acute Cardiovasc Care. 2016;5(3):231-242.
7. Buta BJ, Walston JD, Godino JG, et al. Frailty assessment instruments: systematic characterization of the uses and contexts of highly-cited instruments. Ageing Res Rev. 2016;26:53-61.

8. Afilalo J, Karunananthan S, Eisenberg MJ, Alexander KP, Bergman H. Role of frailty in patients with cardiovascular disease. Am J Cardiol. 2009;103(11):1616-1621.

9. de Vries NM, Staal JB, van Ravensberg CD, Hobbelen JS, Olde Rikkert MG, Nijhuis-van der Sanden MW. Outcome instruments to measure frailty: a systematic review. Ageing Res Rev. 2011;10(1): $104-114$.

10. Rockwood K, Mitnitski A. Frailty defined by deficit accumulation and geriatric medicine defined by frailty. Clin Geriatr Med. 2011;27(1): $17-26$.

11. Wilhelmson K, Duner A, Eklund K, et al. Design of a randomized controlled study of a multi-professional and multidimensional intervention targeting frail elderly people. BMC Geriatr. 2011;11:24.

12. Eklund K, Wilhelmson K, Gustafsson H, Landahl S, Dahlin-Ivanoff S. One-year outcome of frailty indicators and activities of daily living following the randomised controlled trial: "Continuum of care for frail older people". BMC Geriatr. 2013;13:76.

13. Eklund K, Wilhelmson K, Landahl S, Dahlin-Ivanoff S. Screening for frailty among older emergency department visitors: validation of the new FRESH-screening instrument. BMC Emerg Med. 2016;22;16(1):27.

14. Reuben DB. Warning signs along the road to functional dependency. Ann Intern Med. 1998;128(2):138-139.

15. Avlund K, Damsgaard MT, Sakari-Rantala R, Laukkanen P, Schroll M. Tiredness in daily activities among nondisabled old people as determinant of onset of disability. J Clin Epidemiol. 2002;55(10):965-973.

16. Fried LP, Ferrucci L, Darer J, Williamson JD, Anderson G. Untangling the concepts of disability, frailty and comorbidity: implications for improved targeting and care. J Gerontol A Biol Sci Med Sci. 2004;59(3): 255-263.

17. Hoogerduijn JG, Schuurmans MJ, Duijnstee MS, de Rooij SE, Grypdonck MF. A systematic review of predictors and screening instruments to identify older hospitalized patients at risk for functional decline. J Clin Nurs. 2007;16(1):46-57.

18. Covinsky KE, Palmer RM, Fortinsky RH, et al. Loss of independence in activities of daily living in older adults hospitalized with medical illnesses: increased vulnerability with age. J Am Geriatr Soc. 2003;51(4): 451-458.

19. Zisberg A, Shadmi E, Gur-Yaish N, Tonkikh O, Sinoff G. Hospitalassociated functional decline: the role of hospitalization processes beyond individual risk factors. $J$ Am Geriatr Soc. 2015;63(1):55-62.

20. Baztán JJ, Suárez-García FM, López-Arrieta J, Rodríguez-Mañas L, Rodríguez-Artalejo F. Effectiveness of acute geriatric units on functional decline, living at home, and case fatality among older patients admitted to hospital for acute medical disorders: meta-analysis. $B M J$. 2009;338:b50.

21. Kosse NM, Dutmer AL, Dasenbrock L, Bauer JM, Lamoth CJ. Effectiveness and feasibility of early physical rehabilitation programs for geriatric hospitalized patients: a systematic review. BMC Geriatr. 2013;13:107.

22. Chippendale TL, Bear-Lehman J. Enabling "aging in place" for urban dwelling seniors: an adaptive or remedial approach? Phys Occup Ther Geriatr. 2010;28(1):57-62.

23. Turner G, Clegg A; British Geriatrics Society; Age UK; Royal College of General Practitioners. Best practice guidelines for the management of frailty: a British Geriatrics Society, Age UK and Royal College of General Practitioners report. Age Ageing. 2014;43(6):744-747.

24. Ellis G, Whitehead MA, O'Neill D, Langhorne P, Robinson D. Comprehensive geriatric assessment for older adults admitted to hospital. Cochrane Database Syst Rev. 2011;7:CD006211.

25. Ekdahl AW, Wirehn AB, Alwin J, et al. Costs and effects of an ambulatory geriatric unit (the AGe-FIT Study): a randomized controlled trial. J Am Med Dir Assoc. 2015;16(6):497-503.

26. Prestmo A, Hagen G, Sletvold O, et al. Comprehensive geriatric care for patients with hip fractures: a prospective, randomised, controlled trial. Lancet. 2015;385(9978):1623-1633. 
27. SBU. Comprehensive geriatric assessment and care of frail elderly. Stockholm: Swedish Council on Health Technology Assessment (SBU); 2014. SBU report no 221 (in Swedish). Available from: http://www. sbu.se/upload/Publikationer/Content0/1/Akutvard_aldre.pdf; 2013. Accessed May 7, 2016.

28. Ellis G, Marshall T, Ritchie C. Comprehensive geriatric assessment in the emergency department. Clin Interv Aging. 2014;9:2033-2043.

29. Johansson ME, Johansson P. Multisjuka äldre med upprepade vårdtillfällen bör läggas in direkt. Läkartidningen. 2012;109(20-21): 1022-1023 [in Swedish].

30. Ekerstad N, Karlson BW, Dahlin-Ivanoff S, et al. Is the acute care of frail elderly patients in a comprehensive geriatric assessment unit superior to conventional acute medical care? Clin Interv Aging. 2017;12:1-9.

31. Sonn U, Asberg KH. Assessment of activities of daily living in the elderly. A study of a population of 76-year-olds in Gothenburg, Sweden. Scand J Rehabil Med. 1991;23(4):193-202.

32. Katz S, Ford AB, Moskowitz RW, Jackson BA, Jaffe MW. Studies of illness in the aged. The index of ADL: a standardized measure of biological and psychosocial function. JAMA. 1963;185:914-919.
33. Sonn U. Longitudinal studies of dependence in daily life activities among elderly persons. Scand J Rehabil Med Suppl. 1996;34:1-35.

34. Jakobsson U, Karlsson S. Predicting mortality with the ADL-staircase in frail elderly. Phys Occup Ther Geriatr. 2011;29(2):136-147.

35. Charlson M, Pompei P, Ales KL, MacKenzie CR. A new method of classifying prognostic comorbidity in longitudinal studies: development and validation. J Chronic Dis. 1987;40(5):373-383.

36. Frenkel WJ, Jongerius EJ, Mandjes-van Uitert MJ, van Munster BC, de Rooij SE. Validation of the Charlson comorbidity index in acutely hospitalized elderly adults: a prospective cohort study. $J$ Am Geriatr Soc. 2014;62(2):342-346.

37. Zelada MA, Salinas R, Baztán JJ. Reduction of functional deterioration during hospitalization in an acute geriatric unit. Arch Gerontol Geriatr. 2009;48(1):35-39.

38. Pilotto A, Cella A, Pilotto A, et al. Three decades of comprehensive geriatric assessment: evidence coming from different healthcare settings and specific clinical conditions. J Am Med Dir Assoc. 2017;18(2): 192.e1-192.e11. 


\section{Supplementary material}

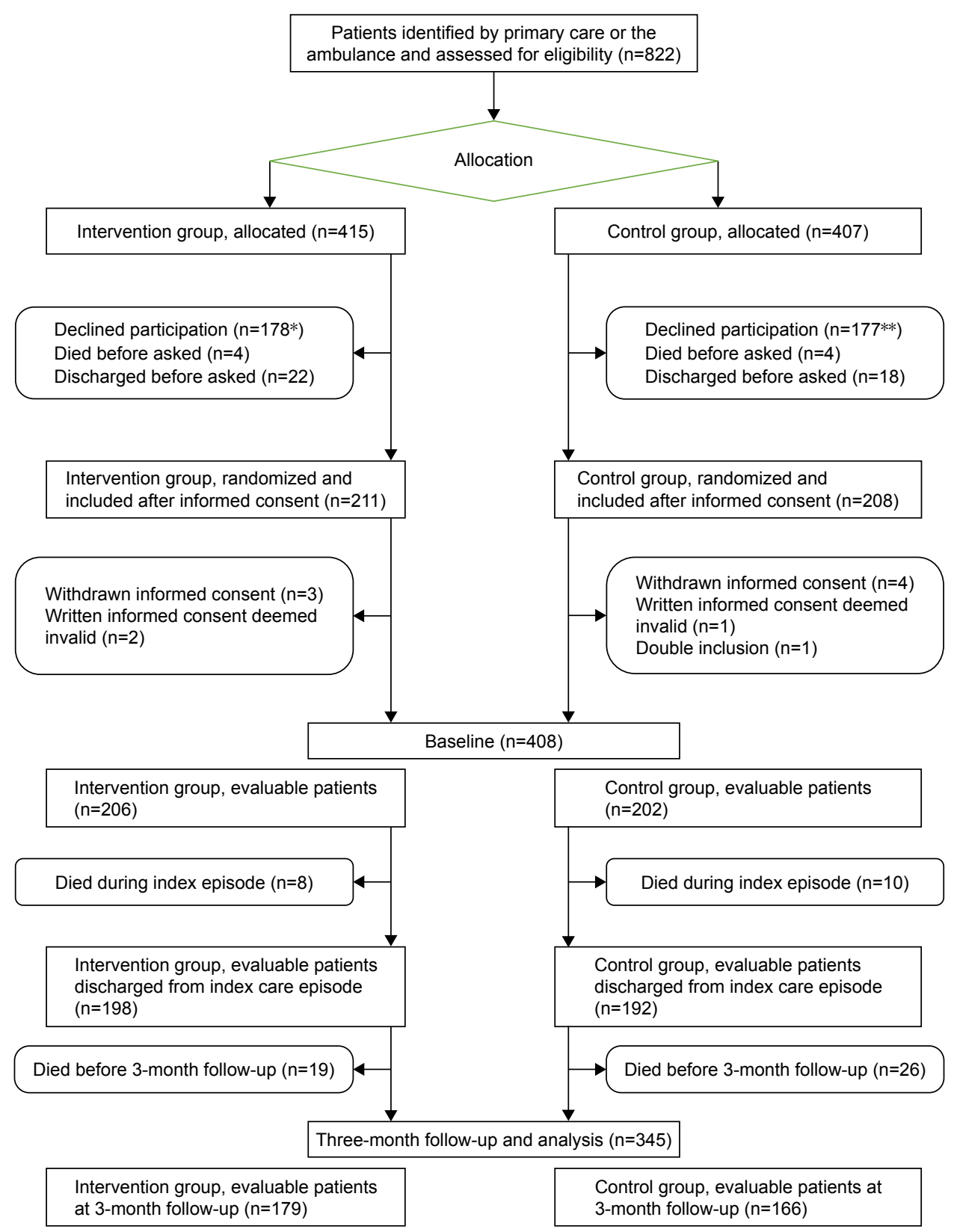

Figure SI Flow chart of participant selection and assessment.

Notes: *Including 10 patients unable to give informed consent; **including six patients unable to give informed consent. Copyright $(0) 2013$. Dove Medical Press. Reproduced from Ekerstad N, Karlson BW, Dahlin-Ivanoff S, et al. Is the acute care of frail elderly patients in a comprehensive geriatric assessment unit superior to conventional acute medical care? Clin Interv Aging. 2017;12:1-9.'

\section{Reference}

1. Ekerstad N, Karlson BW, Dahlin-Ivanoff S, et al. Is the acute care of frail elderly patients in a comprehensive geriatric assessment unit superior to conventional acute medical care? Clin Interv Aging. 2017;12:1-9. 
Clinical Interventions in Aging

\section{Publish your work in this journal}

Clinical Interventions in Aging is an international, peer-reviewed journal focusing on evidence-based reports on the value or lack thereof of treatments intended to prevent or delay the onset of maladaptive correlates of aging in human beings. This journal is indexed on PubMed Central, MedLine,

CAS, Scopus and the Elsevier Bibliographic databases. The manuscript management system is completely online and includes a very quick and fair peer-review system, which is all easy to use. Visit http://www.dovepress. $\mathrm{com} /$ testimonials.php to read real quotes from published authors.

Submit your manuscript here: http://www.dovepress.com/clinical-interventions-in-aging-journal 